\title{
Epidemiology and Incidence of COVID-19-Associated Pulmonary Aspergillosis (CAPA) in a Greek Tertiary Care Academic Reference Hospital
}

\author{
Elisabeth Paramythiotou - George Dimopoulos · Nikolaos Koliakos • \\ Maria Siopi · Sophia Vourli · Spyros Pournaras · Joseph Meletiadis (D)
}

Received: May 14, 2021 / Accepted: June 15, 2021 / Published online: July 14, 2021

(c) The Author(s) 2021

\section{ABSTRACT}

Introduction: Invasive pulmonary aspergillosis is an emerging complication among intensive care unit (ICU) patients with COVID-19 (CAPA). In the present study, all CAPA cases during the first year of the pandemic were reviewed in critically ill patients at a 650-bed tertiary Greek COVID-19 reference hospital.

Methods: Data regarding patients admitted to the ICU of Attikon Hospital in Athens, Greece, between 22 March 2020 and 28 February 2021 with a positive PCR for SARS-CoV-2 infection were reviewed. Clinical and microbiological records were analysed including demographic, clinical, laboratory and radiological features, treatment and outcomes. CAPA was determined according to the recent 2020 ECMM/ISHAM definitions.

Results: A total of 179 patients were admitted in the ICU and $6(3.3 \%)$ patients were diagnosed with CAPA (4 probable and 2 possible CAPA)

E. Paramythiotou - G. Dimopoulos · N. Koliakos 2nd Department of Critical Care, Attikon University Hospital, Medical School, National and

Kapodistrian University of Athens, Athens, Greece

M. Siopi · S. Vourli · S. Pournaras · J. Meletiadis ( $₫)$ Clinical Microbiology Laboratory, Attikon University Hospital, Medical School, National and Kapodistrian University of Athens, 1 Rimini str, Haidari 124 62, Athens, Greece e-mail: jmeletiadis@med.uoa.gr with 5/6 with co-infection with multidrug-resistant (MDR) gram-negative pathogens. No patient had a history of immunosuppression. All suffered from acute respiratory distress syndrome. The median (range) time from intubation to diagnosis was 6 (1-14) days. Five patients had positive Aspergillus cultures in bronchial secretions ( 1 A. fumigatus, 1 A. flavus, 1 A. fumigatus + A. flavus, 1 A. fumigatus + A.terreus and 1 A.terreus) while culture was negative in one patient. All isolates were susceptible to antifungal drugs. Serum galactomannan (GM), pan-Aspergillus PCR and $(1,3)$ $\beta$-D-glucan (BDG) were positive in $4 / 6(67 \%)$, $5 / 6(83 \%, 3 / 5$ in two consecutive samples) and $4 / 6$ (67\%, in consecutive samples) patients, respectively. GM and PCR positive bronchial secretions had GM indices $>9.95$ and PCR $C_{\mathrm{t}}<34$. All were treated with antifungal drugs with 5 out of 6 receiving isavuconazole. Mortality was $67 \%(4 / 6)$ with $1 / 4$ attributed to CAPA (two died as a result of bacterial septic shock and one as a result of multiorgan failure).

Conclusion: The incidence of CAPA in ICU patients was $3.3 \%$ and it was associated with approximately a $17 \%$ attributable mortality in the setting of MDR gram-negative pathogen coinfections.

Keywords: Aspergillosis; COVID-19; ARDS; Lung infection; MDR gram-negative coinfections 


\section{Key Summary Points}

The recent 2020 ECMM/ISHAM definitions were used to define COVID-19associated invasive pulmonary aspergillosis (CAPA).

First study reporting the incidence of CAPA in Greece and in the setting of multidrug-resistant gram-negative bacterial infections globally.

A total of 179 patients were admitted in the ICU and $6(3.3 \%)$ patients were diagnosed with CAPA (4 probable and 2 possible CAPA) all in the second wave of COVID-19 when corticosteroids were used as standard care for patients with COVID19.

Mortality was $67 \%(4 / 6)$ with $1 / 4$ attributed to CAPA.

\section{INTRODUCTION}

During the last 12 months a major pandemic caused by the coronavirus SARS-CoV-2 is running all over the world. A non-negligible percentage of $5-15 \%$ patients with coronavirus disease 2019 (COVID-19) need hospitalization in intensive care units (ICUs) [1]. According to a recent meta-analysis, overall mortality of critically ill patients with COVID-19 has been calculated at $35.5 \% \quad(0-85 \%)$ although the attributable mortality was not reported [2]. Additionally, the incidence of respiratory coinfection with gram-negative pathogens seems to be higher in patients with COVID-19 [3].

Influenza-associated pulmonary aspergillosis (IAPA) has been described in patients with influenza and severe acute respiratory distress syndrome (ARDS) in the ICU and is no longer considered a rare complication [3]. Similarly, early during the pandemic suspected cases of COVID-19-associated pulmonary aspergillosis (CAPA) were described [4]. The airway epithelium is directly damaged by respiratory viruses, enabling Aspergillus to invade tissue. Immune dysregulation, treatment with systemic corticosteroid or anti-interleukin- 6 agents and diffuse alveolar damage in severe SARSCoV-2 infection are included in the risk factors predisposing to ventilator-associated pneumonia and CAPA $[5,6]$. However, the exact incidence of CAPA is not known since the typical host, clinical and radiological factors often used to diagnose invasive fungal diseases are not present in patients with CAPA [7], whereas mycological evidence is based on positive Aspergillus cultures in non-bronchoalveolar lavage (BAL) samples, such as bronchial secretions, tracheal aspirates and sputum, which may reflect colonization rather than infection. Furthermore, it should be acknowledged that CAPA diagnosis was made on the basis of AspICU criteria which were initially developed for IAPA [3, 8] and may not be applicable to CAPA [9]. CAPA-specific diagnostic criteria have been recently developed by the European Confederation of Medical Mycology (ECMM) and the International Society for Human and Animal Mycology (ISHAM) [9] (Table 1). Furthermore, the mortality of CAPA in the setting of co-infections with gram-negative pathogens is unknown.

The aim of this study was to review all CAPA cases during the first year of the pandemic in critically ill patients at "Attikon" University hospital which served as a Greek COVID-19 reference hospital since the first outbreak of the virus and to estimate the incidence and attributable mortality of CAPA based on the new 2020 ECMM/ISHAM criteria.

\section{METHODS}

\section{Patients}

The study was conducted at Attikon University hospital (Athens, Greece) during the COVID-19 pandemic between 22 March 2020 and 28 February 2021. During this period three waves of COVID-19 occurred in Greece, the first between March and July 2020, the second between August and December 2020 while the third is 
Table 1 Different criteria for defining invasive pulmonary aspergillosis. At least one host, one clinical and one mycological factor should be present

\begin{tabular}{|c|c|c|c|}
\hline Definitions & Host factors & Clinical factors & Mycological evidence \\
\hline EORTC/MSGERC & & & \\
\hline $\begin{array}{l}\text { Probable invasive } \\
\text { aspergillosis* } \\
\text { (*Invasive fungal disease } \\
\text { definitions in patients in } \\
\text { ICUs were excluded) }\end{array}$ & $\begin{array}{l}\text { 1. Neutropenia } \\
\text { 2. Haematological } \\
\text { malignancy } \\
\text { 3. Allogeneic stem cell/solid } \\
\text { organ transplantation } \\
\text { 4. Prolonged use of } \\
\text { corticosteroids } \\
\text { ( } \geq 0.3 \mathrm{mg} / \mathrm{kg} \\
\text { for } \geq 3 \text { weeks) } \\
\text { 5. Treatment with T cell } \\
\text { immunosuppressants/ } \\
\text { B cell receptor inhibitors } \\
\text { 6. Inherited severe } \\
\text { immunodeficiency } \\
\text { 7. Acute graft-versus-host } \\
\text { disease grade III or IV }\end{array}$ & $\begin{array}{l}\text { Pulmonary aspergillosis } \\
\text { CT scan = dense, well-circumscribed lesions } \\
\text { with or without a halo sign, air crescent } \\
\text { sign, cavity, or wedge-shaped and segmental } \\
\text { or lobar consolidation } \\
\text { Tracheobronchitis } \\
\text { Bronchoscopic Analysis = tracheobronchial } \\
\text { ulceration, nodule, pseudomembrane, } \\
\text { plaque or eschar }\end{array}$ & $\begin{array}{l}\text { Microscopic detection in } \\
\text { SP, BAL, BS } \\
\text { Aspergillus culture in BAL, } \\
\text { BS } \\
\text { Galactomannan (GM)+ } \\
\text { 1. Single serum, plasma, } \\
\text { BAL, CSF GM } \geq 1.0 \\
\text { 2. Single serum or plasma } \\
\text { GM } \geq 0.7 \text { and } \\
\text { BAL } \geq 0.8 \\
\text { Aspergillus PCR+ } \\
\text { 1. } \geq 2 \text { consecutive plasma, } \\
\text { serum, blood } \\
\text { 2. } \geq 2 \text { consecutive BAL }\end{array}$ \\
\hline AspICU & & & \\
\hline $\begin{array}{l}\text { Putative IPA* } \\
\left({ }^{*} 1 \text { host factor \& } 1 \text { clinical }\right. \\
\text { factor } \& \text { abnormal } \\
\text { imaging } \& \\
\text { lower respiratory tract } \\
\text { Aspergillus }+ \text { culture })\end{array}$ & $\begin{array}{l}\text { 1. Neutropenia } \\
\text { 2. Underlying } \\
\text { haematological } \\
\text { oncological malignancy } \\
\text { treated with cytotoxic } \\
\text { agents } \\
\text { 3. Glucocorticoid treatment } \\
\text { (prednisone equivalent, } \\
20 \text { mg/day) } \\
\text { 4. Inborn/acquired } \\
\text { immunodeficiency } \\
\text { 5. Mycological criterion (see } \\
\text { mycological evidence) }\end{array}$ & $\begin{array}{l}\text { 1. Fever (refractory to } \geq 3 \text { days on } \mathrm{ABx} \text {, } \\
\text { recrudescent after } \geq 2 \text { days defervescence) } \\
\text { 2. Pleuritic chest pain/rub } \\
\text { 3. Dyspnoea } \\
\text { 4. Haemoptysis } \\
\text { 5. Worsening respiratory insufficiency } \\
\text { 6. Combination of the above } \\
\text { AND } \\
\text { Abnormal medical imaging of the lungs } \\
\text { (chest } x \text {-ray or CT scan) }\end{array}$ & $\begin{array}{l}\text { Aspergillus-positive culture } \\
\text { from lower respiratory } \\
\text { tract specimen (entry } \\
\text { criterion) } \\
\text { Semiquantitative } \\
\text { Aspergillus-positive } \\
\text { culture of BAL without } \\
\text { bacterial growth, positive } \\
\text { cytological smear showing } \\
\text { branching hyphae } \\
\text { GM } \geq 0.5 \text { (modified } \\
\text { AspICU) }\end{array}$ \\
\hline
\end{tabular}


Table 1 continued

\begin{tabular}{|c|c|c|c|}
\hline Definitions & Host factors & Clinical factors & Mycological evidence \\
\hline \multicolumn{4}{|l|}{ ECMM/ISHAM } \\
\hline $\begin{array}{l}\text { Proven CAPA } \\
\text { Pulmonary/tracheobroncial } \\
\text { form }\end{array}$ & $\begin{array}{l}\text { Patient with ARDS needing } \\
\text { intensive care and SARS- } \\
\text { CoV-2 PCR }+2 \text { weeks } \\
\text { between hospitalization } \\
\text { and ICU admission or } \\
2-3 \text { days after ICU } \\
\text { admission }\end{array}$ & & $\begin{array}{l}\text { 1. Histopathological and/ } \\
\text { or direct microscopic } \\
\text { detection of Aspergillus } \\
\text { spp. showing invasive } \\
\text { growth and tissue } \\
\text { damage, } \\
\text { 2. Aspergillus + by culture, } \\
\text { microscopy, histology, } \\
\text { PCR from sterile aspirate } \\
\text { or biopsy pulmonary } \\
\text { materials }\end{array}$ \\
\hline $\begin{array}{l}\text { Tracheobronchitis } \\
\text { (probable) }\end{array}$ & $\begin{array}{l}\text { Patient with ARDS needing } \\
\text { intensive care and SARS- } \\
\text { CoV-2 PCR }+2 \text { weeks } \\
\text { between hospitalization } \\
\text { and ICU admission or } \\
\text { 2-3 days after ICU } \\
\text { admission }\end{array}$ & $\begin{array}{l}\text { Bronchoscopic Analysis = tracheobronchial } \\
\text { ulceration, nodule, pseudomembrane, } \\
\text { plaque or eschar }\end{array}$ & $\begin{array}{l}\text { 1. Microscopic detection in } \\
\text { BAL } \\
\text { 2. BAL culture/PCR+ } \\
\text { 3. Serum GM/LFA } \\
\text { index }>0.5 \\
\text { 4. BAL GM/LFA } \\
\text { index } \geq 1.0\end{array}$ \\
\hline $\begin{array}{l}\text { Other pulmonary forms } \\
\text { (probable) }\end{array}$ & $\begin{array}{l}\text { Patient with ARDS needing } \\
\text { intensive care and SARS- } \\
\text { CoV-2 PCR+ } 2 \text { weeks } \\
\text { between hospitalization } \\
\text { and ICU admission or } \\
\text { 2-3 days after ICU } \\
\text { admission }\end{array}$ & $\begin{array}{l}\text { 1. Refractory fever } \\
\text { 2. Pleural rub } \\
\text { 3. Chest pain } \\
\text { 4. Haemoptysis } \\
\text { 5. Combination of the above } \\
\text { AND } \\
\text { Pulmonary infiltrate and/or cavitating } \\
\text { infiltrate (not attributed to another cause) }\end{array}$ & $\begin{array}{l}\text { 1. Microscopic detection in } \\
\text { BAL } \\
\text { 2. BAL culture+ } \\
\text { 3. Serum GM/LFA } \\
\text { index }>0.5 \\
\text { 4. BAL GM/LFA } \\
\text { index } \geq 1.0 \\
\text { 5. } \geq 2 \text { plasma/serum/ } \\
\text { whole blood Aspergillus } \\
\text { PCR+ } \\
\text { 6. } 1 \text { BAL Aspergillus PCR+ } \\
\text { (<36 cycles) } \\
\text { 7. } 1 \text { plasma/ serum/whole } \\
\text { blood Aspergillus PCR+ } \\
\text { and } 1 \text { BAL Aspergillus } \\
\text { PCR+ (any cycle) }\end{array}$ \\
\hline
\end{tabular}


Table 1 continued

\begin{tabular}{|c|c|c|c|}
\hline Definitions & Host factors & Clinical factors & Mycological evidence \\
\hline $\begin{array}{l}\text { Other pulmonary forms } \\
\text { (possible) }\end{array}$ & $\begin{array}{l}\text { Patient with ARDS needing } \\
\text { intensive care and SARS- } \\
\text { CoV-2 PCR }+2 \text { weeks } \\
\text { between hospitalization } \\
\text { and ICU admission or } \\
2-3 \text { days after ICU } \\
\text { admission }\end{array}$ & $\begin{array}{l}\text { 1. Refractory fever } \\
\text { 2. Pleural rub } \\
\text { 3. Chest pain } \\
\text { 4. Haemoptysis } \\
\text { 5. Combination of the above } \\
\text { AND } \\
\text { Pulmonary infiltrate and/or cavitating } \\
\text { infiltrate (not attributed to another cause) }\end{array}$ & $\begin{array}{l}\text { 1. Microscopic detection in } \\
\text { non-BAL } \\
\text { 2. Non-BAL culture+ } \\
\text { 3. } 1 \text { non-BAL GM } \\
\text { index } \geq 4.5 \\
\text { 4. } \geq 2 \text { non-BAL GM } \\
\text { index } \geq 1.2 \\
\text { 5. } 1 \text { non-BAL GM } \\
\text { index } \geq 1.2 \text { and } 1 \text { non- } \\
\text { BAL PCR/LFA }+\end{array}$ \\
\hline
\end{tabular}

$A R D S$ acute respiratory distress syndrome, $B A L$ bronchoalveolar lavage, non-BAL non bronchoscopic BAL, GM galactomannan, $L F A$ lateral flow assay, $B S$ bronchial secretions, $S P$ sputum, $C S F$ cerebrospinal fluid, $C T$ computed tomography, $P C R$ polymerase chain reaction, $I C U$ intensive care unit

ongoing. "Attikon" University hospital is a tertiary 650-bed teaching hospital and referral centre for central and south Greece as well as most of the Aegean islands with a total ICU capacity of 23 beds. During the pandemic all 23 beds were dedicated to mechanically ventilated patients infected by coronavirus, while nonCOVID-19 cases were hospitalized in newly opened ICU beds. Data regarding patients admitted to the ICU with a positive PCR for SARS-CoV-2 infection were reviewed. In our ICU, respiratory samples are routinely collected once a week for surveillance bacterial and fungal cultures. In case of clinical deterioration new cultures are also collected, a BAL is performed if considered necessary and respiratory and serum samples are sent for full mycological diagnostic workup as described below. A CT scan of the chest is performed if the patient can be safely transferred. Clinical records were analysed including demographic, clinical, laboratory and radiological features, treatment and outcomes of patients with CAPA.

The study protocol was approved by the local institutional Review Board and Bioethics Committee (EBA96/15-2-2021).

\section{Samples for Mycological Workup}

Respiratory samples were analysed by direct and fluorescence microscopy using Blankophor $\mathrm{P}$ and cultured in Sabouraud dextrose agar with gentamicin and chloramphenicol plates (SGC2; bioMerieux) incubated at $30^{\circ} \mathrm{C}$ and $37^{\circ} \mathrm{C}$ for up to 3 weeks. Recovered isolates were identified macro-/microscopically to species level. Aspergillus fumigatus sensu stricto (SS) was identified on the basis of growth at $48{ }^{\circ} \mathrm{C}$. Antifungal susceptibility testing (AST) to amphotericin B, caspofungin, micafungin, anidulafungin, isavuconazole, voriconazole, itraconazole and posaconazole was performed in all isolates using the EUCAST E. Def 9.3.2 reference broth microdilution method [10]. Serum and respiratory samples were stored at $-70{ }^{\circ} \mathrm{C}$ until tested for galactomannan (GM), (1,3)- $\beta$-D-glucan (BDG) and Aspergillus DNA (PCR). A commercially available sandwich enzyme-linked immunoassay (Platelia Aspergillus EIA; Bio-Rad Laboratories, Hercules, CA, USA) was used to quantify GM antigen in accordance with the manufacturer's instructions. A result was considered positive when the index value was $\geq 0.5$. BDG was detected with the Dynamiker Fungus BDG assay (Dynamiker Biothechnology- 


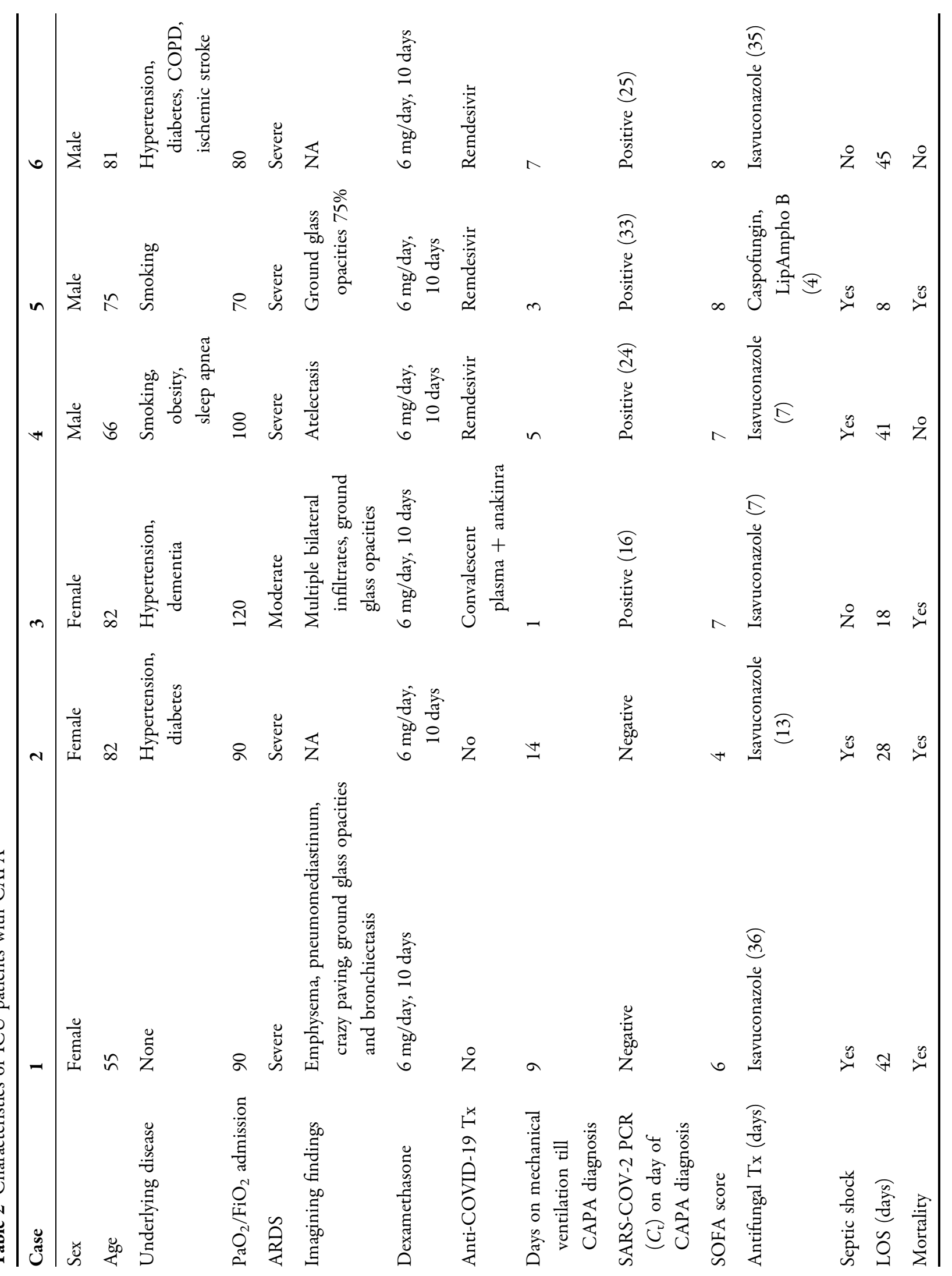




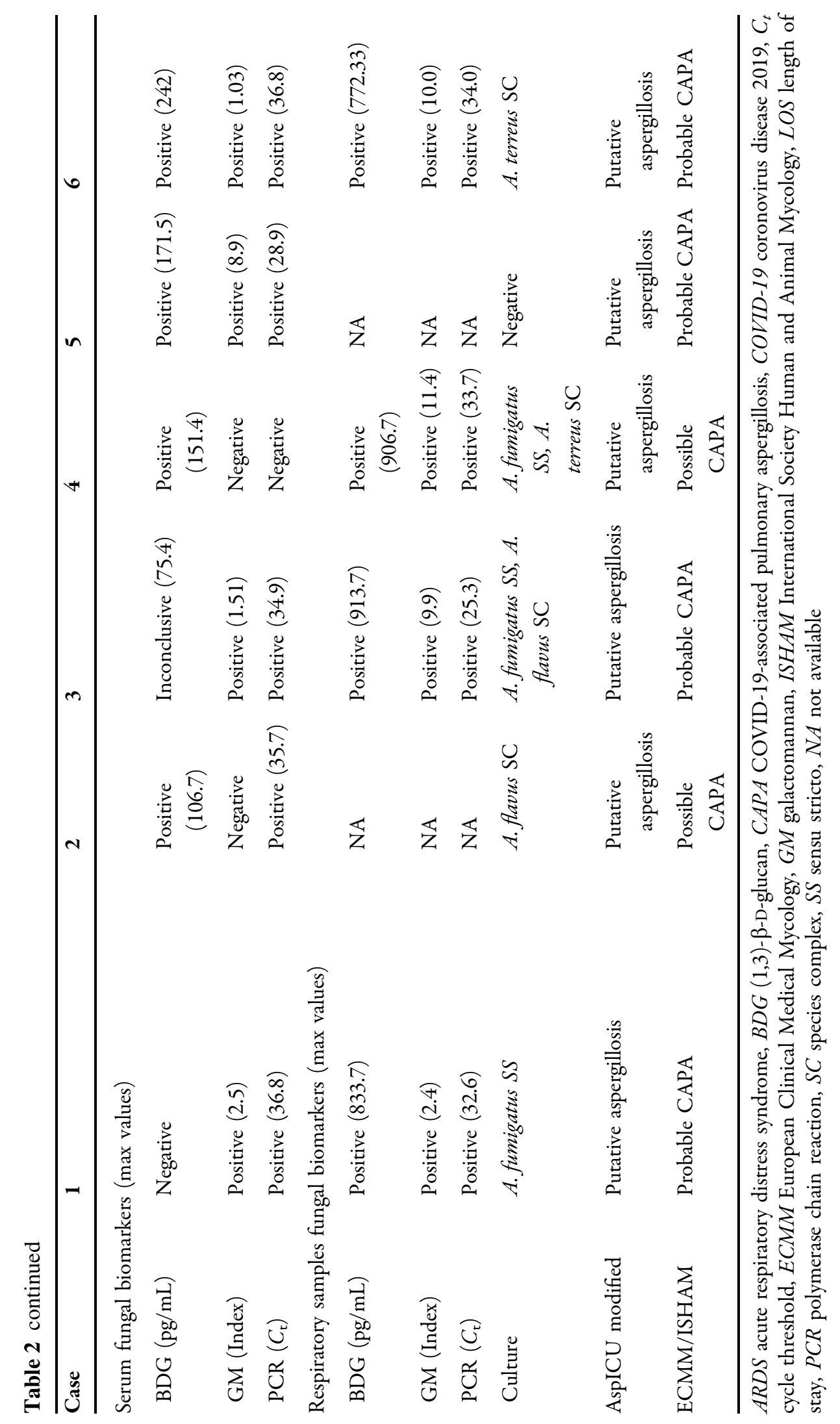



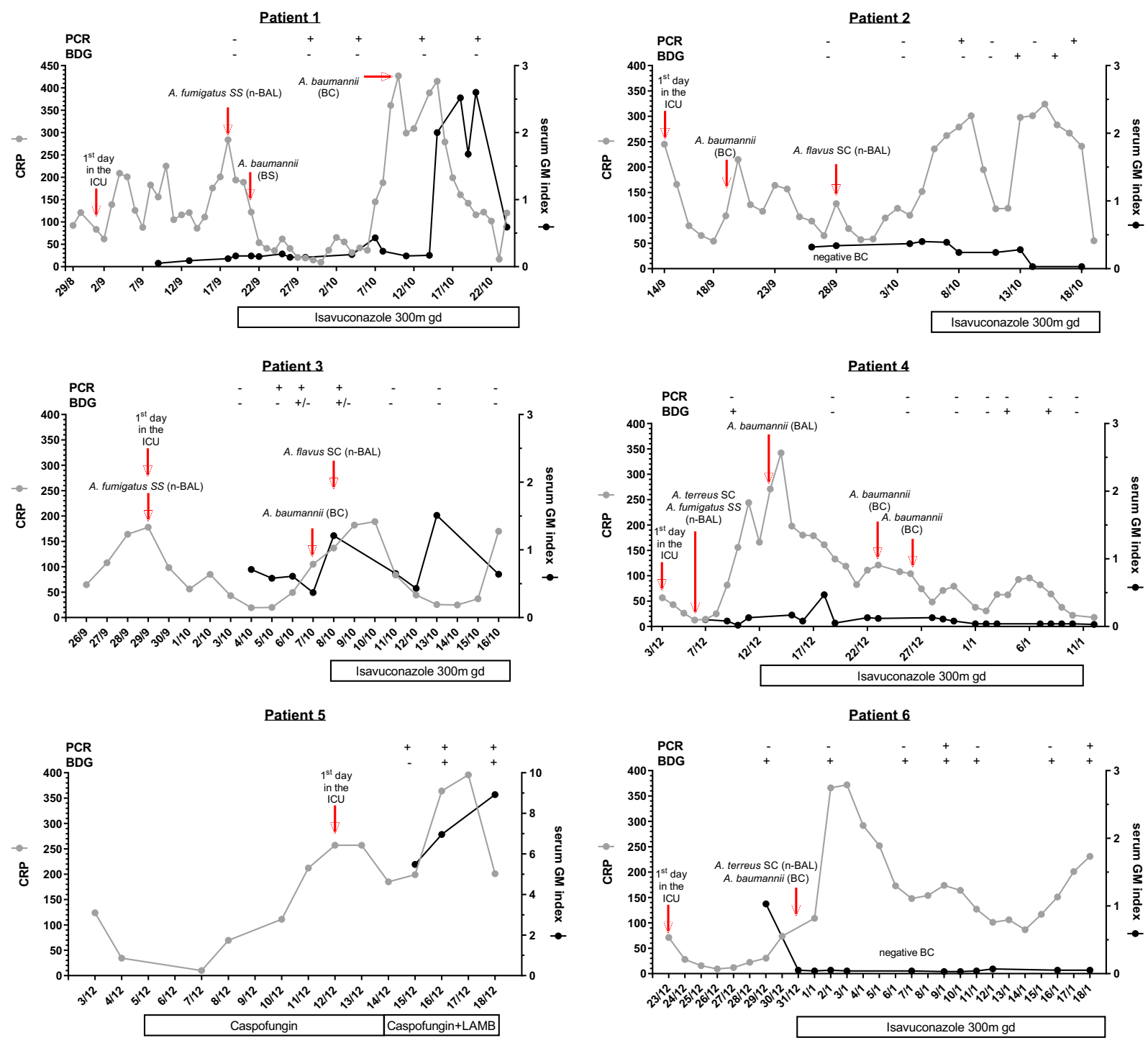

Fig. 1 Kinetics of galactomannan (GM) index and C-reactive protein (CRP) together with microbiological and treatment data for each patient. BDG: $(1,3)-\beta-D-$

glucan, PCR: Aspergillus DNA, BC: bloodculture, BS: bronchial secretion, n-BAL: non bronchoscopic BAL

Tianjin Co, Ltd, China) as recommended by the manufacturer. BDG levels of $\geq 95,70-94$ and $<70 \mathrm{pg} / \mathrm{mL}$ were considered positive, inconclusive and negative results, respectively. Serum assays were performed in duplicate. A real-time PCR was developed in line with the published European Aspergillus PCR Initiative recommendations for serum [11]. Aspergillus DNA was extracted from $1 \mathrm{~mL}$ serum after enzymatic (incubation with protease $\mathrm{K}$ at $56^{\circ} \mathrm{C}$ for $10 \mathrm{~min})$ and mechanical (15 min vortex

with glass beads) pre-treatment using the High Pure Viral Nucleic Acid Large Volume Kit (Roche, Athens, Greece) according to the manufacturer's instructions. Real-time PCR was performed with a previously validated assay (2Asp assay) using Aspergillus-specific primers (ASF1 and ADR1) targeting the 28S rRNA gene and an Aspergillus-specific hydrolysis probe (ASP28P). All PCR runs included a positive (spiked human sera) and a negative (water in place of DNA extract) control. When no 

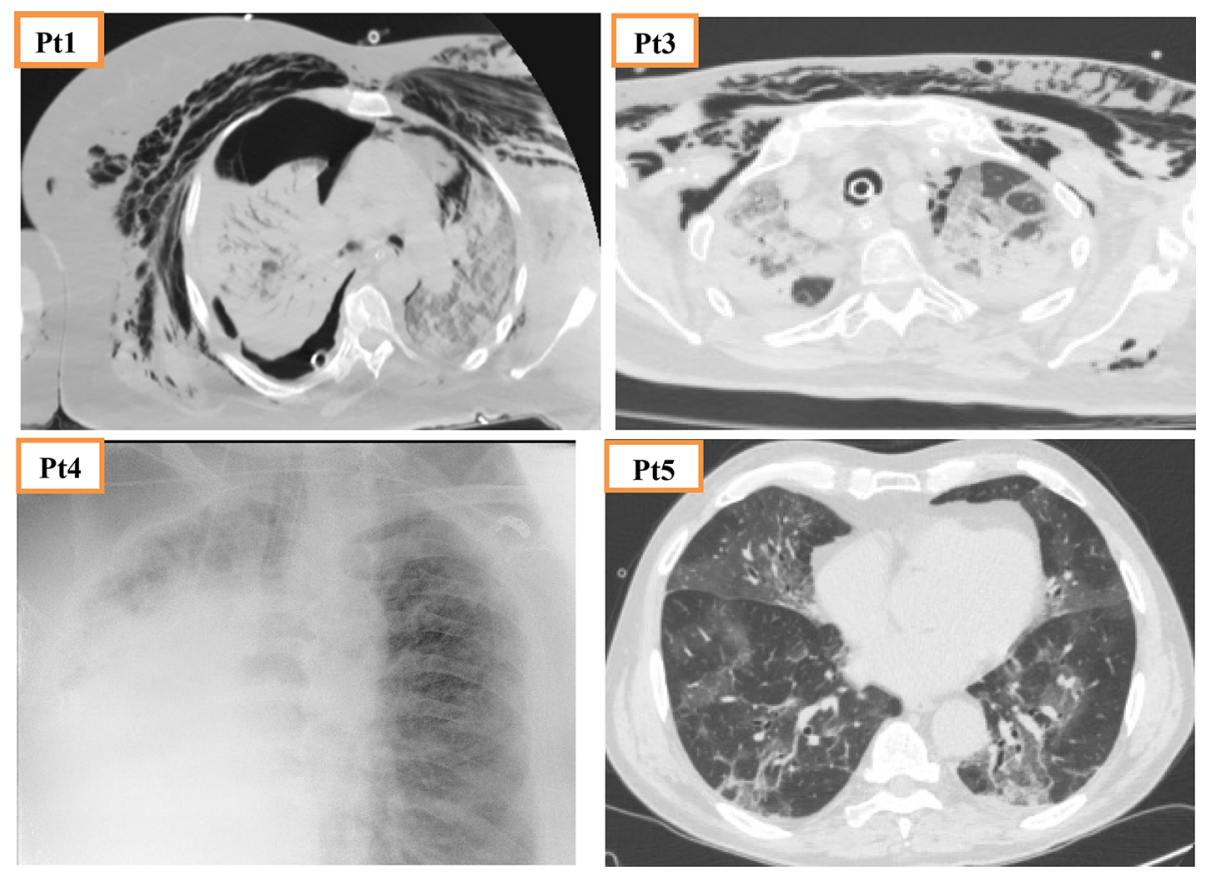

Fig. 2 Lung images of patients with CAPA. Patient 1. Subcutaneous emphysema, pneumomediastinum, crazy paving, ground glass opacities and bronchiectasis (ICU day 30). Patient 3. Subcutaneous emphysema, pneumothorax, ground glass opacities (ICU day 13). Patient 4. Chest

X-ray showing a large right lung atelectasis (ICU day 9). Patient 5. CT chest showing ground glass opacities with bronchiectatic regions and thickening of intralobular septal (ICU day 2)

amplification was observed after 43 PCR cycles $\left(C_{t}\right)$, the sample was considered negative by PCR [12].

\section{Definitions}

CAPA was classified by clinical, mycological and radiological criteria according to both the modified AspICU [3, 8] and 2020 ECMM/ISHAM criteria [9] (Table 1). Classification according to the revised European Organization for Research and Treatment of Cancer and the Mycoses Study Group Education and Research Consortium (EORTC/MSGERC) 2020 criteria [7, 13] was not feasible because none of the included patients presented any of the required host risk factors. Moreover, no case could be classified as proven invasive pulmonary aspergillosis (IPA) because neither lung biopsy nor autopsy was performed.

\section{RESULTS}

During the study period 1161 patients with COVID-19 were admitted to the hospital with a total of 179 admissions in the ICU, 35 in the first wave. Among the 179 critically ill patients, six (3.3\%) had clinical and mycological characteristics of invasive aspergillosis and were treated accordingly. Detailed clinical and radiological characteristics of all patients are presented in Table 2, whereas the time course of infection and treatment is shown in Fig. 1. Of note, all cases were noticed during the second wave. BAL was performed in one patient for therapeutic reasons. Median age was 78 years (55-82) and 50\% were male. All patients received dexamethasone $6 \mathrm{mg} /$ day for 10 days, $3 / 6$ remdesivir and 1/6 anakinra + convalescent plasma. No patient had a history of immunosuppression. All patients were diagnosed with ARDS according to Berlin definition [14]. The median time from intubation to diagnosis of 
CAPA was 6 days (range 1-14). Signs of clinical deterioration and septic shock have been recorded in four patients at the time of diagnosis. Multidrug-resistant Acinetobacter baumanni was isolated from the blood of $5 / 6$ patients. Five patients had positive Aspergillus cultures in bronchial secretions (1 A. fumigatus species complex (SS), 1 A. flavus SC, 1 A. fumigatus $\mathrm{SS}+A$. flavus SC, 1 A. fumigatus $\mathrm{SS}+A$. terreus SC and $1 A$. terreus SC) while culture was negative in one patient. Serum GM index and Aspergillus PCR were positive in $4 / 6$ patients (67\%) and 5/6 (83\%) although PCR was positive in two consecutive samples in 3 patients. BDG was positive in sera of $4 / 6$ patients with CAPA (all 4 with consecutive samples). Furthermore, GM and PCR were positive in $4 / 4$ bronchial secretions analysed for GM and Aspergillus DNA with GM indices $>9.95$ and PCR $C_{\mathrm{t}}<34$. Detailed microbiology data are presented in Table 2. According to the AST all isolates were susceptible to voriconazole and isavuconazole. Three patients completed the treatment. Mortality was as high as $67 \%(4 / 6)$ and $1 / 4$ was attributed to CAPA.

\section{Patient 1}

A 55-year-old woman was admitted to our ICU and was intubated 10 days later. She was extubated after a week, but she had to be intubated again 2 days later. GM and Aspergillus PCR were positive in serum. A. fumigatus SS was then isolated in bronchial secretions. Her deterioration was partly attributed to a putative infection by the fungus, so she was started on isavuconazole 2 days after the result of the culture. Her respiratory function was ameliorated. Multidrug-resistant A. baumanni was cultured from blood on day 40. On day 53, she presented pyopneumothorax and CT scan was performed showing subcutaneous emphysema, pneumomediastinum, crazy paving, ground glass opacities and bronchiectasis (Fig. 2). She was treated for pyopneumothorax but she presented multiple septic shocks and finally died.

\section{Patient 2}

An 82-year-old woman was admitted to the infectious diseases department because of fever and hypoxemia caused by SARS-CoV-2. Ten days later the patient was intubated and transferred to our ICU. A. flavus SC was isolated in the bronchial secretions. Although GM in serum was negative, PCR and BDG were positive in two samples. Isavuconazole was started 8 days after the first isolation of the mould. Multidrug-resistant A.baumanni was cultured from blood on day 5 in the ICU. The patient presented deterioration of respiratory and hemodynamic function and died 13 days later.

\section{Patient 3}

An 82-year-old woman was admitted to the ICU 2 days after her admission to the infectious diseases department being positive for SARSCoV-2. She was under treatment with convalescent plasma therapy and anakinra. The first sample of bronchial secretions was positive for $A$. fumigatus $S S$ and the second sample taken by mini-BAL 9 days later was positive for $A$. flavus SC. Multidrug-resistant A. baumanni was cultured from blood on day 8 in the ICU. A CT scan was performed showing multiple bilateral infiltrates and ground glass opacities covering $50-75 \%$ of lung parenchyma (Fig. 2). The GM antigen and Aspergillus PCR in the serum were positive. The patient was started on isavuconazole 9 days after the first culture, but her respiratory function was further deteriorated and she died 9 days later.

\section{Patient 4}

A 66-year-old man was admitted to the ICU 7 days after his admission to the infectious diseases department with dyspnea, weakness and fever and a positive SARS-CoV-2 with severe ARDS and hemodynamic instability. He was treated with remdesivir. On day 3 he developed septic shock that was managed with adequate antibiotic therapy and vasopressors. On day 10, a therapeutic bronchoscopy was performed because of a right lung atelectasis (Fig. 2). 
A. baumanni was isolated from the BAL. GM and PCR were negative in serum and positive in bronchial secretions from where $A$. fumigatus SS and A.terreus SC were isolated. The patient received isavuconazole starting on day 6 of the diagnosis. A. baumanni was cultured from blood on day 20. His situation ameliorated and after a tracheostomy was performed, he was able to be transferred for further treatment to the clinical floor.

\section{Patient 5}

A 75-year-old man was admitted to the infectious diseases department with dyspnea, weakness and fever and a test positive for SARS-CoV2 . The CT scan of the chest showed ground glass opacities occupying about $75 \%$ of lung parenchyma (Fig. 2). During the next 9 days his situation deteriorated so he was intubated and admitted to the ICU with severe ARDS and multiorgan failure. GM and Aspergillus PCR in serum were positive. The patient was initially treated with caspofungin and then with liposomal amphotericin B, but he died because of multiorgan failure.

\section{Patient 6}

An 81-year-old man was admitted to the ICU after 4 days of hospitalisation in the infectious diseases department for COVID-19 infection. On day 6 in the ICU he presented fever, elevated inflammatory markers and deterioration of respiratory function. GM was positive in serum and 2 days after culture of bronchial secretions were positive for $A$. terreus SC. Isavuconazole was started. On day 8, A. baumanni was cultured from blood. The patient's condition ameliorated, a tracheostomy was performed and he was transferred to a step-down unit.

\section{DISCUSSION}

The coronavirus pandemic first appeared in Greece on 26 February 2020, about 2 months after the outbreak of the disease in China. In a population of just over 11 million, Greek authorities have recorded 263,689 confirmed cases of the disease and a death toll of 8093 (3\%) as of March 2021 [13]. Patients with several comorbidities, including chronic obstructive pulmonary disease, diabetes, hypertension, coronary heart disease, cerebrovascular diseases and malignancy present a higher rate of severe illness [15]. Several cases of CAPA have been described globally. According to a recent study, a total of 151 cases of patients on mechanical ventilation have been published until now [16]. To our knowledge these are the first six cases of CAPA in critically ill patients ever described in Greece and the first one in the setting of gramnegative bacterial infections.

The incidence of CAPA in our single-centre study was as high as 3.3\%, similar to the studies by Machado et al. [17] and Lamoth et al. [18], but considerably lower in comparison to other studies [19-21]. Of note most of those studies did not use the recently published CAPA-specific criteria defined by ECMM/ISHAM. On the basis of those criteria, the rates of possible and probable CAPA were $1.1 \%$ and $2.2 \%$, respectively, in our centre. For the two patients with possible CAPA, the first patient had Aspergillus $\mathrm{PCR}+$ in serum but not in two consecutive samples and positive Aspergillus non-BAL culture and for the second patient GM, Aspergillus PCR and cultures were positive in bronchial secretions. In a recent study performing extensive diagnostic testing in the UK, rates of 5\% and $15 \%$ of proven/probable and possible diagnosis of CAPA, respectively, were reported [22]. Significant differences are observed between countries. Possible explanations could include geographical differences, different risk factors and different applied diagnostic algorithms [19].

COVID-19 pneumonia per se has been suggested as a possible risk factor for invasive aspergillosis. Furthermore, treatment with tocilizumab and dexamethasone, usage of broadspectrum antibiotics and dysregulated immune response have been proposed as predisposing factors favouring Aspergillus infections [23] in the setting of COVID-19. A cumulative azithromycin dose of at least $1500 \mathrm{mg}$ and a high dose of dexamethasone have also been 
mentioned as possible risk factors associated with CAPA in a recent French multicentre cohort study $[24,25]$. Our patients received a total azithromycin dose exceeding $1500 \mathrm{mg}$. Treatment with medicine other than dexamethasone could possibly explain the absence of Aspergillus cases during the first wave along with the small number of patients in our study.

Differentiating between colonization and invasive Aspergillus disease is difficult, especially in immunocompetent patients. Therefore, a full mycological workup is imperative. GM detection is more sensitive in BAL than in blood in non-neutropenic patients who are more likely to have a non-angioinvasive IPA, as opposed to neutropenic patients $[7,26]$. It has been emphasized that since GM detection is not validated on non-BAL respiratory samples, its use may contribute to overdiagnosis of IPA in patients with COVID-19. According to the recent $2020 \mathrm{ECMM} / \mathrm{ISHAM}$ consensus criteria, a non-BAL GM index of $>4.5$ or twice $>1-2$ is suggested [9]. Indeed, in 3/4 cases where nonBAL GM was available, indices were $>9.95$. Interestingly, while in most studies serum GM and PCR were negative in patients with CAPA as opposed to IAPA [16], in our patients the serum GM index and Aspergillus PCR were positive in $4 / 6$ patients $(67 \%)$ and $5 / 6(83 \%)$ although PCR was positive in two consecutive samples only in 3 patients. BDG was positive in sera of $4 / 6$ patients with CAPA (all 4 with consecutive samples). Some authors suggested that receiving hydroxychloroquine could negatively influence the GM measurement in serum [27]. Of note, none of our patients received hydroxychloroquine since all cases were registered in the second wave of the disease. Another explanation could be the severity of COVID-19 infection as in three of our patients the SARS-CoV-2 inoculum as quantified by RT-PCR $C_{t}$ values was rather low (persistent high viral load) at the time of Aspergillus infection, a parameter rarely reported in the literature [28].

The impact of Aspergillus treatment on survival of patients with CAPA is currently unknown. The overall mortality was $67 \%(4 / 6$ patients). A similar cause of death and a high mortality are reported in earlier studies $[25,29]$. However, in the setting of gram-negative multidrug-resistant bacterial infections the attributable mortality of CAPA was only $17 \%$ (1/ 6 patients) as bacterial septic shock and multiorgan failure was the cause of death for the $3 / 4$ patients who died. Nevertheless antifungal treatment has to be implemented and, while voriconazole remains the main treatment for IPA, we preferred the use of isavuconazole owing to its lack of nephrotoxicity, fewer drug-drug interactions observed than with voriconazole, especially with COVID-19 addressed therapies such as remdesivir [29]. Furthermore, there was no need for monitoring drug levels. Most patients in the literature have been treated with voriconazole and more rarely with echinocandins or amphotericin B. Treatment with voriconazole is probably associated with a better prognosis compared to echinocandins or amphotericin B [28]. Suggested treatment duration according to the guidelines is between 6 and 12 weeks. Three of our patients $(50 \%)$ were treated for more than 2 weeks.

In conclusion, the strength of our study was that many patients with CAPA had positive biomarkers in serum in combination with positive cultures in respiratory samples which increased the certainty of diagnosis of invasive aspergillosis in ICU patients with COVID-19 and the fact that it provides one of the first estimates of CAPA incidence and attributable mortality using the CAPA-specific criteria recently determined by ECMM/ISHAM in 2020 in the setting of gram-negative bacterial infections. Among the limitations are that our data are derived from only one centre and the definite diagnosis lacks histological confirmation. Further studies are needed in order to (a) elucidate the biological mechanisms underlying the association between COVID-19 and CAPA and (b) to define the true incidence of the disease. Since difficulties in diagnosing CAPA have contributed to increased mortality rates via delayed diagnosis, a high level of awareness of ICU physicians for CAPA might prove lifesaving. Thus, early identification and treatment need to be implemented. 


\section{ACKNOWLEDGEMENTS}

We thank the participants of the study.

Funding. No funding or sponsorship was received for this study or publication of this article.

Authorship. All named authors meet the International Committee of Medical Journal Editors (ICMJE) criteria for authorship for this article, take responsibility for the integrity of the work as a whole, and have given their approval for this version to be published.

Authors' Contribution. Supervision, data analysis, writing-review and editing, J.M.; methodology, experiments, data analysis, writing-original draft preparation, E.P., N.K., M.S., S.V.; writing-review and editing, G.D., S.P.

Disclosures. Elisabeth Paramythiotou, George Dimopoulos, Nikolaos Koliakos, Maria Siopi, Sophia Vourli, Spyros Pournaras and Joseph Meletiadis have nothing to disclose.

Compliance with Ethics Guidelines. The study protocol was approved by the local institutional Review Board and Bioethics Committee (EB $\Delta 96 / 15-2-2021)$.

Data Availability. The datasets analysed during the current study are available from the corresponding author on reasonable request.

Open Access. This article is licensed under a Creative Commons Attribution-NonCommercial 4.0 International License, which permits any non-commercial use, sharing, adaptation, distribution and reproduction in any medium or format, as long as you give appropriate credit to the original author(s) and the source, provide a link to the Creative Commons licence, and indicate if changes were made. The images or other third party material in this article are included in the article's Creative Commons licence, unless indicated otherwise in a credit line to the material. If material is not included in the article's Creative Commons licence and your intended use is not permitted by statutory regulation or exceeds the permitted use, you will need to obtain permission directly from the copyright holder. To view a copy of this licence, visit http://creativecommons.org/licenses/by$\mathrm{nc} / 4.0 /$.

\section{REFERENCES}

1. Wu Z, McGoogan JM. Characteristics of and important lessons from the coronavirus disease 2019 (COVID-19) outbreak in China: summary of a report of 72314 cases from the Chinese Center for Disease Control and Prevention. JAMA. 2020;323: 1239-42.

2. Armstrong RA, Kane AD, Kursumovic E, Oglesby FC, Cook TM. Mortality in patients admitted to intensive care with COVID-19: an updated systematic review and meta-analysis of observational studies. Anaesthesia. 2021;76:537-48.

3. Schauwvlieghe AFAD, Rijnders BJA, Philips N, et al. Invasive aspergillosis in patients admitted to the intensive care unit with severe influenza: a retrospective cohort study. Lancet Respir Med. 2018;6: 782-92.

4. Bartoletti M, Bartoletti M, Pascale R, et al. Epidemiology of invasive pulmonary aspergillosis among intubated patients with COVID-19: a prospective study. Clin Infect Dis. 2020. https://doi. org/10.1093/cid/ciaa1065/5876990.

5. RECOVERY Collaborative Group, Horby P, Lim W, et al. Dexamethasone in hospitalized patients with covid-19. N Engl J Med. 2021;384:693-704.

6. Somers EC, Eschenauer GA, Troost JP, et al. Tocilizumab for treatment of mechanically ventilated patients with COVID-19. Clin Infect Dis. 2020 [Online Epub ahead].

7. Donnelly JP, Chen SC, Kauffman CA, et al. Revision and update of the consensus definitions of invasive fungal disease from the European Organization for Research and Treatment of Cancer and the Mycoses Study Group Education and Research Consortium. Clin Infect Dis. 2020;71:1367-76.

8. Blot SI, Taccone FS, Van Den Abeele AM, et al. A clinical algorithm to diagnose invasive pulmonary aspergillosis in critically ill patients. Am J Respir Crit Care Med. 2012;186:56-64.

9. Koehler P, Bassetti M, Chakrabarti A, et al. Defining and managing COVID-19-associated pulmonary aspergillosis: the $2020 \mathrm{ECMM} / \mathrm{ISHAM}$ consensus 
criteria for research and clinical guidance. Lancet Infect Dis. 2021;21:e149-62.

10. Arendrup MC, Meletiadis J, Mouton JW, Lagrou K, Hamal P, Guinea J. Method for the determination of broth dilution minimum inhibitory concentrations of antifungal agents for conidia forming moulds, EUCAST definitive document EDef 9.3.2. https://www.eucast.org/fileadmin/src/media/PDFs/ EUCAST_files/AFST/Files/EUCAST_E_Def_9.3.2 Mould_testing_definitive_revised_2020.pdf. 2020.

11. White PL, Mengoli C, Bretagne S, et al. Evaluation of Aspergillus PCR protocols for testing serum specimens. J Clin Microbiol. 2011;49:3842-8.

12. Siopi M, Karakatsanis S, Roumpakis C, et al. Performance, correlation and kinetic profile of circulating serum fungal biomarkers of invasive aspergillosis in high- risk patients with hematologic malignancies. J Fungi. 2021;7:211-35.

13. Coronavirus Update (Live): $113,040,671$ Cases and 2,505,740 Deaths from COVID-19 Virus Pandemic-Worldometer. 2021. https://www. worldometers.info/coronavirus/

14. Ranieri VM, Rubenfeld GD, Thompson BT, et al. Acute respiratory distress syndrome: the Berlin definition. JAMA. 2012;307:2526-33.

15. Li J, He X, Yuan Y, et al. Meta-analysis investigating the relationship between clinical features, outcomes, and severity of severe acute respiratory syndrome coronavirus 2 (SARS-CoV-2) pneumonia. Am J Infect Control. 2021;49:82-9.

16. Meijer EFJ, Dofferhoff ASM, Hoiting O, Meis JF. COVID-19-associated pulmonary aspergillosis: a prospective single-center dual case series. Mycoses. 2021;64:457-64.

17. Machado M, Valerio M, Álvarez-Uría A, et al. Invasive pulmonary aspergillosis in the COVID-19 era: an expected new entity. Mycoses. 2021. https://doi. org/10.1111/myc. 13213 .

18. Lamoth F, Glampedakis E, Boillat-Blanco N, Oddo $\mathrm{M}$, Pagani J-L. Incidence of invasive pulmonary aspergillosis among critically ill COVID-19 patients. Clin Microbiol Infect. 2020;26:1706-8.
19. van Arkel ALE, Rijpstra TA, Belderbos HNA, van Wijngaarden P, Verweij PE, Bentvelsen RG. COVID19-associated pulmonary aspergillosis. Am J Respir Crit Care Med. 2020;202:132-5.

20. Rouzé A, Martin-Loeches I, Povoa P, et al. Relationship between SARS-CoV-2 infection and the incidence of ventilator-associated lower respiratory tract infections: a European multicenter cohort study. Intensive Care Med. 2021;47:188-98.

21. Koehler P, Cornely OA, Böttiger BW, et al. COVID19 associated pulmonary aspergillosis. Mycoses. 2020;63:528-34.

22. Borman A, Palmer M, Fraser M, et al. COVID-19associated invasive aspergillosis: data from the UK National Mycology Reference Laboratory. J Clin Microbiol. 2020;59:e02136-e2220.

23. Costantini C, van de Veerdonk FL, Romani L. Covid-19-associated pulmonary aspergillosis: the other side of the coin. Vaccines. 2020;8:1-9.

24. Falces-Romero I, Ruiz-Bastián M, Díaz-Pollán B, et al. Isolation of Aspergillus spp. in respiratory samples of patients with COVID-19 in a Spanish tertiary care hospital. Mycoses. 2020;63:1144-8.

25. Dellière $S$, Dudoignon $E$, Fodil $S$, et al. Risk factors associated with COVID-19-associated pulmonary aspergillosis in ICU patients: a French multicentric. Clin Microbiol Infect. 2020;27:790.e1-790.e5.

26. Matthay MA, Thompson BT, Ware LB. The Berlin definition of acute respiratory distress syndrome: should patients receiving high-flow nasal oxygen be included? Lancet Respir Med. 2021;2600:26-9.

27. Verweij PE, Gangneux J-P, Bassetti M, et al. Diagnosing COVID-19-associated pulmonary aspergillosis. Lancet Microbe. 2020;1:e53-5.

28. Apostolopoulou A, Garrigos ZE, Vijayvargiya P, Lerner AH, Farmakiotis D. Invasive pulmonary aspergillosis in patients with SARS-CoV-2 infection: a systematic review of the literature. Diagnostics. 2020;10:807.

29. McCreary EK, Pogue JM. Coronavirus disease 2019 treatment: a review of early and emerging options. Open Forum Infect Dis. 2020;7:1-11. 